\title{
Particularities of occupational health and safety management in the police environment
}

\author{
Adrian-Constantin ACHIM \\ The Bucharest University of Economic Studies, Bucharest, Romania \\ achim_adrian@yahoo.com
}

\begin{abstract}
To other professions, in law enforcement, due to the diversity and complexity of police activity, policemen are daily exposed to various dangers resulting from the risky nature of their working environment. Thus, police work must be carried out in the most aggravating circumstances, often with limited staff and only having a few seconds to make critical decisions: whenever using the legal means, specific equipment, intercepting or immobilizing offenders, acting against various violations of the law, police officers are exposed to a very high number of occupational risks, compared to other civil professions. Despite the fact that public security environment risks are constantly evaluated by specialized workers and dedicated tools, compared to the policeman, this activity almost does not happen and it is mostly evasive taking into consideration that this area is within the competence of the high level manager and it is conducted by the human resources structures in the police units. Although this approach is totally wrong, these entities are the only ones in charge of controlling, mitigating or eliminating work related risks generated by police activity. This paper makes a brief assessment of the risks associated with the police operational work, taking into account the indicators taken and analyzed from the existing statistics of the Romanian Ministry of Internal Affairs, while offering new solutions in mitigating risks concerning the physical security of police workers.
\end{abstract}

Keywords: safety management, organizational health, risk management, occupational stress hazards, organizational factors and stressors, policing work risk factors.

\section{Introduction}

Police officers and military personnel within The Romanian Ministry of Internal Affairs are mainly a heterogeneous population regarding risk factors and health indicators.

In Romania, similar to other European countries, police departments are composed of various divisions or units who are responsible for a wide range of law enforcement activities and for this reason policemen are exposed to different tasks and work conditions. The range of responsibilities and work environments among policemen leads to differences in levels of psychological perceptions and demands, taking into consideration the fact that in some cases policemen work alone and have relative autonomy in fulfilling their tasks and others are working in teams and rely on the support of other colleagues or superiors.

Another aspect may refer to the hierarchical structure of the police environment, like some policemen are hierarchically better placed and have higher social status than others due to the nature of their work, level of autonomy, education or earnings.

In order to understand how combinations of workplace and personal factors affects physical and mental health of the police force, it is important to analyze which are the different combinations of work risk factors that may be health relevant for each police unit. The work of police officers is fundamental to the achievement of balance in society, and it is therefore important to understand any dangers or associated work risk factors regarding this category of personnel. 
This paper has taken into account an analysis of relevant police work risk indicators corroborated with provisions of the normative acts in force in the field of security and health at work and those of the work injuries assessment existing at the level of the human resources department of the Romanian Ministry of Internal Affairs. To accomplish this paper, all the specific indicators on work accidents concerning the personnel of the military and police units were gathered, evaluated and collated at the highest level.

All statistical indicators were arranged and organized in a personal database so that they could be easily compared with the existing annual reports at the level of the labor inspectorates.

For the last three years, because of the massive outflows caused by retirement of police workers and of police detachments to other structures, no clear database on work accidents in units and structures of the ministry was created, this aspect, as well as the assessments related to this period will be reconsidered starting with this year.

\section{Literature review}

In police work, danger is always a possibility, and it is highly unpredictable, because the potential to become a victim of a violent encounter, the need for backup from other colleagues and the legitimate use of violence to accomplish the police mandate, all contribute to a subculture that stresses bravery, which is ultimately related to the perceived and actual dangers of policing (Grossman, 2017).

According to the US National Law Enforcement Officers Memorial Fund there are over 20 death related causes that can be prefigured as risk factors in the police work process: aircraft accident, auto crash, beaten, bicycle accident, boating accident, bombrelated incident, drowned, electrocuted, fall, horse-related accident, job-related illness, motorcycle crash, poisoned, shot, stabbed, strangled, struck by falling object, struck by train, struck by a vehicle terrorist attack.

Although, studies investigating health-related risk factors in law enforcement usually assess the term 'police officers' or 'firefighters', implying a group homogenous in terms of exposure to work environments (Morash et al., 2006; Violanti et al., 2006), those two categories include very different subfields of policing or firefighting, each with different sets of work risk factors. For example, the most common health risk for the majority of police officers is low physical activity due to the sedentary nature of their work, yet this is not entirely true for the special forces units (Hartley et al., 2011; Tharkar et al., 2008).

The work of police officers involves repeated and long-term exposure to heavy workloads, high job strain or violence, all of which have a potentially negative impact on physical and mental health and this is particularly true for police officers and firefighters who in addition to workplace stress also deal with physical, chemical, biological and psychological hazards while on duty (Guidotti, 2016; Violanti et al., 2006; Bolstad-Johnson et al., 2000; Melius, 2000).

Policing and firefighting are generally regarded as high-risk and high-stress occupations by a large number of studies, because workers belonging to those two categories of staff spend significant time working outside their workplaces and managing unpredictable and urgent situations resulting from a high-stress work environment (Laursen et al., 2000). If several studies have suggested a correlation between shift work 
and cardiovascular disease or other negative health outcomes (Feuer et al., 1986; Sardinas et al., 1986), other more recent Western studies have found that police officers had several risk factors for cardiovascular disease, including personal factors such as smoking, alcohol consumption, hypertension, obesity and work-related factors such as night duties, high job stress, workplace violence and long work shifts (Zimmerman, 2012; Franke et al., 1997). Additionally, several studies have noted that factors that contribute to the stress of firefighters have been identified as being lack of sleep, job insecurity, workplace conflicts, physical environment and levels of alcohol consumption (Lee et al., 2009; Ha et al., 2008).

The longevity of most law enforcement careers, the stress levels from exposure to danger and traumatic situations can have detrimental effects on law enforcement officers (Chapin et al., 2008). Enforcement officers also suffer significant medical, physical, and mental problems the longer they stay in service (Hassell and Brandl, 2009) or within their workplace environments (Keinan and Malach-Pines, 2007). In addition, law enforcement personnel working prolong hours and alternative work shifts suffer from lack of sleep and many other medical issues, which could manifest as negative stressors. For all the reasons above, researches have shown police officers and law enforcement personnel have a shorter life expectancy than the general population (Violanti et al., 2013).

Some studies involving US police officers and firefighters indicated that the two categories of staff have higher mortality and morbidity rates compared with the general population, particularly for cardiovascular diseases. Franke, Collins and Hinz (1998) reported that the incidence of cardiovascular diseases is higher among police officers than in the general civilian population (31.4\% versus $18.4 \%)$ and a study involving US firefighters found that cardiovascular diseases was the primary cause of death in the line of duty, accounting for approximately $45 \%$ of the on-duty fatalities (Soteriades et al., 2011).

Another interesting fact regarding work risk factors concerning policing, is that some studies among US police officers (Storch and Panzarella, 1996) and deputy marshals (Newman and Rucker-Reed, 2004) indicated that organizational factors such as poor management or work conditions were more frequently identified as negative stressors than potential violence or exposure to human misery.

Even if, comparable research regarding the European police families is scarce, a study of Dutch police officers also indicated that organizational stressors, especially poor management, were mentioned more often than stressors related to the job content (Kop et al., 1999). Also, for Scottish police officers, the highest levels of stress were related to organizational factors such as perceived staff shortage and inadequate resources (Biggam et al., 1997).

\section{Methodology}

The period that was taken into account for the processing of the indicators refers to 20082014 and for accomplishing this paper it was chosen to take into account the term 'work accident' as defined in article 5 of the Romanian Law no. 319 of 2006 relating to health and safety at work defined as "the violent injury of the body as well as the acute professional intoxication occurred during the work process or the discharge of the service duties caused by temporary incapacity for work for at least three days, invalidity or death". 
According to the provisions of article 30 of the same law were considered as 'labor accidents' those occurred during organized cultural and sport activities, during the movement from the worker's home to the workplace and vice versa, during the movement between two places of work, during work break time, under the conditions provided by the law.

It is worth mentioning that in order to notice significant trends, a first analysis of the predominant causes of law enforcement accidents was carried out for the entire data collection, without making any differentiation depending on unit categories. For the accuracy of the data analyzed, only work accidents completed in that year were taken into account for each year, with reference to resumption of activity, work incapacity or death, even if they occurred in the previous year.

The paper contains some comparisons made with the frequency indexes related to the number of accidents registered per 1,000 employees and severity indexes indicating the number of work incapacity days per 1,000 employees, resulting from the national data reported by the labor inspectorates.

\section{Results and discussions}

According to the data analysis and the evaluated cases, the total number of work accidents in the units subordinated to the Romanian Ministry of Internal Affairs doubled in 2009 compared to 2008, with accidents mainly resulting in temporary incapacity to work (97\%).

The frequency of accidents that resulted in the death of the employee was constant in 2008 and 2009, slightly below the national frequency. Thus, in 2009, in the ministry's units, there were 5 fatal accidents: one death due to an aggression resulting in the shooting of a border police officer, one death of a policeman who was doing his duty on a road traffic control mission, the death of a policeman while driving the car and two deaths of a policeman and a military serviceman as a result of road accidents.

At the same time, the number of accidents with more than one victim increased by $60 \%$ in 2009 compared to 2008, and taking into account the $1 / 36$ ratio between the ministry staff and the other national civil employees, this is a very high ratio. There were eight collective labor accidents in 2009, which resulted in 27 victims, and in other labor sectors there were 22 collective accidents, resulting in 97 victims. In 2009, the frequency index of the accidents registered in the units of the Romanian Ministry of Internal Affairs increased by $68 \%$ compared to 2008 , reaching a double compared with the level of the calculated national frequency index. Consequently, on the background of an increase in the average duration index, there was also an increase in the severity index, regarding the number of days of work incapacity per 1,000 employees, which also exceeded the national average.

Most of the accidents and the highest increase in the frequency compared to 2008 were recorded by the fire emergency units and police divisions from the Romanian National Police. Accidents occurred during missions in some emergency situations due to the worker's wrong maneuvers, or as a result during sport activities or other physical training. The accidents recorded at the level of the National Romanian Police units were due to traffic accidents, as a result of aggression or employee's wrong maneuvers. 
As for 2010 , the total number of work accidents increased by over $25 \%$ compared to 2009. These accidents resulted in temporary incapacity for work (96\%). In 2010, there were no accidents recorded resulting in obvious disability for the personnel, but two accidents resulting in disabled invalidity were recorded, subsequently confirmed by a medical decision for a third-degree incapacity, respectively a military serviceman from a emergency unit fell from a fence when trying to save a cat from a tree and a traffic policeman became a victim of a car accident during his daily mission.

Compared to 2009, the average duration index remained constant and just below the level of the same indicator calculated at national level, namely 41 working days rest in the units of the ministry compared to 63 working days rest at the national level.

The number of collective injuries declined slightly in 2010 compared to the previous year, but taking into account the ratio of the ministry staff compared with the employees in other sectors of labor, it is still very high. Taking into consideration that in 2010 the number of work accidents in the ministry increased by about $25 \%$ compared to 2009 , the frequency index of registered accidents increased with 0.35 as compared to 2009 , at a double level to the calculated frequency index at national level, which in 2010 was 2.2 and in 2009 was 2.1.

Consequently, on the background of a relatively high number of accidents, there was also a high value of the gravity index, which was 1.7 times higher than the national average. The analysis of the distribution of work accidents shows that most of these were recorded at subordinated divisions belonging to the National Romanian Police and Emergency Inspectorate. Thus, the two distributions are completely different, except for the large proportions recorded in both situations for accidents caused by the wrong actions of the employee, which actually shows the different nature of the main dangers to which the staff are exposed. Regarding the Emergency inspectorates, work hazards are present in the lifesaving missions and sport activities, as while police officers are exposed to dangers when conducting road traffic activities or facing physical aggression when defending public order.

For the year 2011, there were 255 victims of work accidents. Taking into consideration the analysis of the available data, the total number of work accidents remained constant compared to the previous year, but their frequency increased on the background of a staff shortage, reaching very high values compared to the national average, namely 1.83 injured per 1,000 employees compared to 0.69 injured per 1,000 employees, estimated at national level. Due to the relatively large number of accidents, there was also a higher value of the severity index, which was at least twice the value calculated for the national level.

The accidents are mainly caused by temporary work incapacity in $96 \%$ of the cases, there was one accident whose victim has resumed his work activity as limited and six accidents whose victims retired after being classified with a disability, of which three victims as a result of physical aggression to which they were subjected while performing their duties.

In the years 2009-2011, the frequency of fatal accidents was approximately constant (of 0.03-0.05 deaths per 1,000 employees), close to the national frequency. In 2011, there were recorded four fatal accidents, all of them being car accidents. Compared to 2010, the average duration index increased from 41 working days rest in 2010 to 47 working days 
rest in 2011, and the number of collective accidents dropped from eight accidents in 2009 to seven accidents in 2010, reaching four accidents in 2011.

The highest values of the frequency index, which are above the average registered at the level of the ministry and well above the national average of 0.69 per 1,000 employees, are attributable to the emergency system units, of 2.62 per 1,000 employees and for the police units, of 2.21 per 1,000 employees. This finding reflects the high occupational risk of the two areas of activity, police and firefighting or emergency which far exceed the degree of risk of other occupations or work activities nationwide.

Noteworthy is that the accident frequency index of the emergency units remained the same as in the previous year, maintaining a very high level. At the same time, the frequency of accidents in the Romanian Police units has increased significantly over the analyzed time frame. Frequency variations were also recorded in other categories of personnel, namely gendarmes and border police officers, but the corresponding number of work accidents is too small to allow a concrete statistical analysis by type of accidents.

In 2011, specific work risk factors were maintained, as well as the risks derived from physical training activities and the specific risks resulting from traffic control activities and physical aggression following an outrage.

In 2012, there were 256 accidents, of which 229 occurred during work and 27 were road accidents, respectively on the home-work route or vice versa. Labor accidents were mainly caused by temporary incapacity for work in $97 \%$ of cases. Thus, seven work-related deaths were recorded, resulting from car accidents - four deaths, two deaths due to traffic control accidents and one death due to physical aggression.

Different from previous years, in 2012 most of the accidents were due to aggression, and with regard to the category of personnel that included the injured, there was a major change in the sense that $50 \%$ of the injured were police officers, and $21 \%$ gendarmes, which shows that the number of work accidents has increased due to the increase of the crime rate and the growing aggression of the citizens towards police personnel.

In 2013, in the work process there were 233 employees injured, as a result of 227 individual accidents and two collective injuries. Similar to 2012, accidents have resulted in temporary work incapacity in $97 \%$ of the cases. There were seven deaths as a result of road accidents in two cases, traffic control in three cases and due to the fulfillment of daily missions in two cases.

The Labor Force Work Frequency Index for the staff of the Romanian Ministry of Internal Affairs was 1.75 per 1,000 employees, which doubled compared to the one calculated nationwide. The frequency index calculated in dependence with the units belonging to the ministry reveals high risks particularly posed by emergency personnel as well as policemen, keeping in high percentage accidents caused by aggressions (21\%) and those resulting from labor process (39\%).

The severity index of work-related accidents, which reflects the impact of the consequences of accidents on the employer's activity, is 73 working days rest per 1,000 employees, this index being differentiated between structures, reflecting the combination of specific risk levels and the number of staff within the organization. Therefore, high values of this indicator in 2013 have been recorded for emergency personnel (88 working days rest 
per 1,000 employees), policemen (76 working days rest per 1,000 employees) and gendarmes (of 55 working days rest per 1,000 employees).

In 2014, the total number of employees injured at work was 286, all recorded with temporary work incapacity. The work injury frequency index for the Ministry of Internal Affairs personnel was 2.09 per 1,000 employees, roughly doubled the national average. The frequency index calculated reveals very high occupational risks to which police personnel and emergency personnel are exposed. According to the type of accidents, $23 \%$ resulted from physical aggressions and 19\% from car accidents.

The severity index was 110 working days rest per 1,000 employees, compared to 73 working days rest per 1,000 employees in the previous year, with high levels of risks being identified in police, emergency and gendarmerie units.

\section{Conclusion}

Processed data highlights the high occupational risk of the two areas of activity, policing, firefighting or emergency situations, which far exceeds the level of danger of other occupational families or work activities nationwide. Different forms of work accidents shows that most of these were recorded at subordinated divisions belonging to the National Romanian Police and Emergency Inspectorate, the two distributions being completely different, except for the large proportions recorded in both situations for accidents caused by the wrong maneuvers of employees, which demonstrates the different nature of the main dangers to which the staff are exposed. Regarding the Emergency inspectorates, work hazards are present in the life-saving missions and sport activities, as while policemen are exposed to dangers when conducting road traffic activities or facing physical violence in the external work environment.

During the analyzed period, the total number of accidents gradually increased, on average by $50 \%$ and the number of cases with temporary work incapacity maintaining an average of over $95 \%$. Although, the number of deaths caused by work accidents has remained relatively low over the years, the severity and frequency indices have doubled, especially since 2012, when significant organizational departures took place and the crime rate has increased. These figures compared with the international scientific papers reviewed, show that even if there are many differences between police organizations, laws and socio-cultural aspects regarding the examined countries, much of the scientific research about policing related work and risk factors analyzed in this paper indicates important similarities between the different national police institutions all over the world, providing a starting point for further research, although there are still a multitude of limitations regarding the lack of statistical data or similar scientific articles related to the police working environment in the European Union states.

A good starting point for filling this information gap, would be like police managers identify risks related with police work, assess, categorize and collate them in databases, organizing them by severity, frequency and consequences. In order to be more consistent it should be developed effective controls to mitigate health and work risks factors, implement those controls and evaluate their effectiveness. This can be done by designing computer applications with predictive functions, evaluation and publicity, in order to each police manager could see those job positions involving high risk activity at work. 
This could also be done by reevaluating the occupational standards for the existing positions in relation to on-the-job risks, and after reviewing these positions, through standardization of similar positions with unique job descriptions or similar occupational standards.

\section{References}

Ardinas, A., Miller, JW., Hansen, H. (1986). Ischemic heart disease mortality of firemen and policemen. Am J Public Health, 76(9), 1140-1141.

Biggam, F.H., Power, K.G., MacDonald, R.R., Carcary, W.B., Moodie, E. (1997). Self-perceived occupational stress and distress in a Scottish police force. Work and Stress, 11(2), 118-133.

Bolstad-Johnson, DM., Burgess, JL., Crutchfield, CD. (2000). Characterization of firefighter exposures during fire overhaul. AIHAJ, 46(3), 636-641.

Chapin, M., Brannen, S.J., Singer, M.I., Walker, M. (2008). Training police leadership to recognize and address operational stress. Police Quarterly, 11(3), 338-352.

Darabonț, Al., Pece, St., Dascălescu, A., (2001), Occupational Health and Safety Management (volume I, II), Ed. Agir.

Feuer, E. , Rosenman, K. (1986). Mortality in police and firefighters in New Jersey. Am J Ind Med, 9(6), 517-527.

Franke, WD., Collins, SA., Hinz, PN. (1998). Cardiovascular disease morbidity in an Iowa law enforcement cohort, compared with the general Iowa population. J Occup Environ Med, 40(5), 441-444.

Franke, WD., Cox, DF., Schultz, DP. (1997). Coronary heart disease risk factors in employees of Iowa's Department of Public Safety compared to a cohort of the general population. Am J Ind Med, 31(6), 733-737.

Guidotti, TL. (2016). Health Risks and Fair Compensation in the Fire Service. Springer.

Grossman, D. (2017). The Police Culture and Work Stress (Chapter 8), Sage Publishing.

Ha, J., Kim, DI., Seo, BS. (2008). Job stress and psychosocial stress among firefighters. Korean J Occup Environ Med, 20(2), 104-111.

Hartley, TA., Burchfiel, CM., Fekedulegn, D. (2011). Associations between police officer stress and the metabolic syndrome. Int J Emerg Ment Health, 13(4), 243-256.

Hassell, K.D., Brandl, S.G. (2009). An examination of the workplace experiences of police patrol officers: The role of race, sex, and sexual orientation. Police Quarterly, 12(4), 408-430.

Keinan, G., Malach-Pines, A. (2007). Stress and burnout among personnel: Outcomes, and intervention strategies. Criminal and Behavior, 34(3), 380-398.

Kop, N., Euwema, M., Schaufeli, W. (1999). Burnout, job stress, and violent behaviour among Dutch police officers. Work and Stress, 13(4), 326-340.

Laursen, B., Ekner, D., Simonsen, EB. (2000). Kinetics and energetics during uphill and downhill carrying of different weights. Appl Ergon, 31(2), 159-166.

Lee, DH., Jeon, HJ., Shin, DH. (2009). Association between job stress and the Minnesota multiphasic personality inventory in firefighters. Korean J Occup Environ Med, $21(4), 324-336$.

Melius, J. (2000). Occupational health for firefighters. Occup Med, 16(1), 101-108. 
Morash, M., Haarr, R., Kwak, DH. (2006). Multilevel Influences on Police Stress. Journal of Contemporary Criminal Justice, 22(1), 26-43.

Newman, D.W., Rucker-Reed, M.L. (2004). Police stress, state-trait anxiety, and stressors among U.S. marshals. Journal of Criminal Justice, 32(6), 631-641.

National Law Enforcement Officers Memorial Fund Causes of Law Enforcement (2018). Deaths Over the Past Decade, updated March 15, 2018, retrieved from http://www.nleomf.org/facts/officer-fatalities-data/causes.html.

Romanian Law no. 360/2002 regarding Policemen Statute.

Romanian Law no. 319/2006 on safety and health at work.

Soteriades, ES., Smith, DL., Tsismenakis, AJ. (2011). Cardiovascular disease in US firefighters: a systematic review. Cardiol Rev, 19(4), 202-215.

Storch, J.E., Panzarella, R. (1996). Police stress: State-trait anxiety in relation to occupational and personal stressors. Journal of Criminal Justice, 24(2), 99-107.

Tharkar, S., Kumpatla, S., Muthukumaran, P. (2008). High prevalence of metabolic syndrome and cardiovascular risk among police personnel compared to general population in India. J Assoc Physicians India, 56, 845-849.

Violanti, JM., Fekedulegn, D., Hartley, TA., (2013). Life expectancy in police officers: a comparison with the U.S. general population. Int J Emerg Ment Health, 15(4), 217228.

Violanti, JM. , Andrew, ME. , Burchfiel, CM. (2006). Posttraumatic stress symptoms and subclinical cardiovascular disease in police officers. Int J Stress Manag, 13(4), 541554.

Violanti, JM., Burchfiel, CM., Miller, DB., Andrew, ME., Dorn, J., Wactawski-Wende, J., Beighley, CM., Pierino, K., Joseph, PN., Vena, JE., Sharp, DS., Trevisan, MA. (2006). The Buffalo Cardio-Metabolic Occupational Police Stress pilot study: methods and participant characteristics. Epidemiol, 16(2), 148-156.

Zimmerman, FH. (2012). Cardiovascular disease and risk factors in law enforcement personnel: a comprehensive review. Cardiol Rev, 20(4), 159-166. 